\title{
Silverleaf whitefly present in the San Joaquin Valley
}

\author{
Ned M. Gruenhagen $\square$ Thomas M. Perring $\square$ Larry G. Bezark \\ David M. Daoud $\square$ Thomas F. Leigh
}

\begin{abstract}
The silverleaf whitefly (formerly "sweetpotato whitefly strain B," see p. 7) has caused extensive damage in Southern California's Imperial, Coachella, and Palo Verde valleys. It is now present in the San Joaquin Valley and is raising increasing concern among California's agricultural interests.
\end{abstract}

In 1991, the silverleaf whitefly severely damaged agricultural plantings in California's southern desert valleys; losses in the Imperial Valley alone were estimated at \$129.7 million between May 1991 and April 1992. Damaged crops included alfalfa, broccoli, cotton, melons, and tomatoes.

The whitefly causes damage directly when it removes plant sap during feeding and indirectly when it excretes a "honey$\mathrm{dew}^{\prime \prime}$ that becomes the medium for sooty mold fungus to grow. In addition, this whitefly is associated with squash silverleaf and tomato irregular ripening, two plant physiological disorders that have been recorded in California (California Agriculture, November-December 1991). This whitefly also vectors tomato mottle geminivirus, a damaging pathogen found in Florida, but not known to occur in California.

Aside from occasional observations of the silverleaf whitefly in Central and Northern California and western Riverside County, economic losses attributable to it have been limited to southern desert agricultural regions: the Coachella, Imperial, and Palo Verde valleys. Here we provide evidence of its occurrence in the San Joaquin Valley, where extensive acreages of the same crops that it damaged in the southern desert are grown annually.

\section{Surveys}

In autumn of 1992, two surveys were conducted to determine the extent of the whitefly infestation in Kern County. During the first survey, in early September, we sampled one field each of broccoli, cantaloupe, and lettuce, three potato fields and thirteen cotton fields near Bakersfield that were infested with whiteflies (table 1; fig.1). Leaves were collected from plants in the field as well as from four different weed species adjacent to these crops. Samples of leaves from each location were bagged, cooled, and transported to UC Riverside.

Because the silverleaf whitefly is morphologically indistinguishable from the sweetpotato whitefly, we relied on an electrophoretic technique to identify the species present in the valley. The procedure, called isoelectric focusing (IEF), was used to detect allelic differences between individuals allowing us to differentiate between the two whiteflies. (See related article, p. 7.) From each of the 19 sample sites, several leaves with late instar nymphs were placed in a petri dish, and adults were allowed to emerge. Up to 15 adult females were collected from each location and individually subjected to IEF.

In addition to identifying the species, we evaluated the amount of parasitism on whiteflies present from each plant type sampled. To accomplish this, we used a binocular microscope to observe up to 100 late-stage immature whiteflies from randomly selected leaves collected at each location and categorized them as third instar nymphs, fourth instar nymphs, emerged nymphs, or dead nymphs. Additionally, those individuals parasitized by Encarsia spp. or Eretmocerus spp. were enumerated. Parasitized nymphs were excised intact with a small section of plant tissue and placed in individual gelatin capsules until the parasitoid emerged and more specific identification could be accomplished. Whiteflies distinguished as Trialeurodes spp., which could include the greenhouse whitefly; $T$. vaporariorum, or the banded winged whitefly, T. abutilonia, were counted in our samples, but they were categorized only as to whether or not they were parasitized.

Enzyme profiles from our IEF indicated that all individuals sampled were silverleaf whiteflies. In addition to this survey, we detected the whitefly on outdoor plants in Visalia, and it was found in Fresno by James Duffus of the U.S. Department of Agriculture, Agricultural Research Service, Salinas. Thus, we are confident that it is widely distributed in the San Joaquin Valley. The full impact of this insect on the
Cantaloupe fruit covered with honeydew and sootymold fungus. 


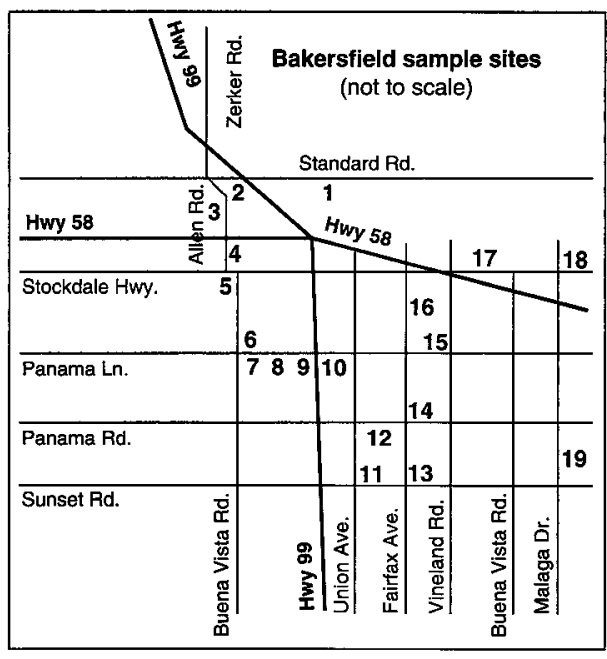

Fig. 1. Samples were taken in first survey from sites near Bakersfield to assess presence of silverleaf whiteflies by isoelectric focusing (IEF).

valley's diverse agricultural ecosystem is unknown, but in the Imperial Valley the crops most damaged were melons and cotton. Feeding by this whitefly can lead to defoliation of these two crops and can cover cotton lint with honeydew, thereby increasing ginning costs. Growers of these two crops, in addition to growers of tomato (because of the possible occurrence of irregular ripening), should be particularly alert to whitefly infestations. However, because other far less damaging whitefly species also infest San Joaquin Valley crops, producers should have whiteflies in their fields identified before enacting control programs.

Natural enemies often help reduce damage by pest populations, as witness

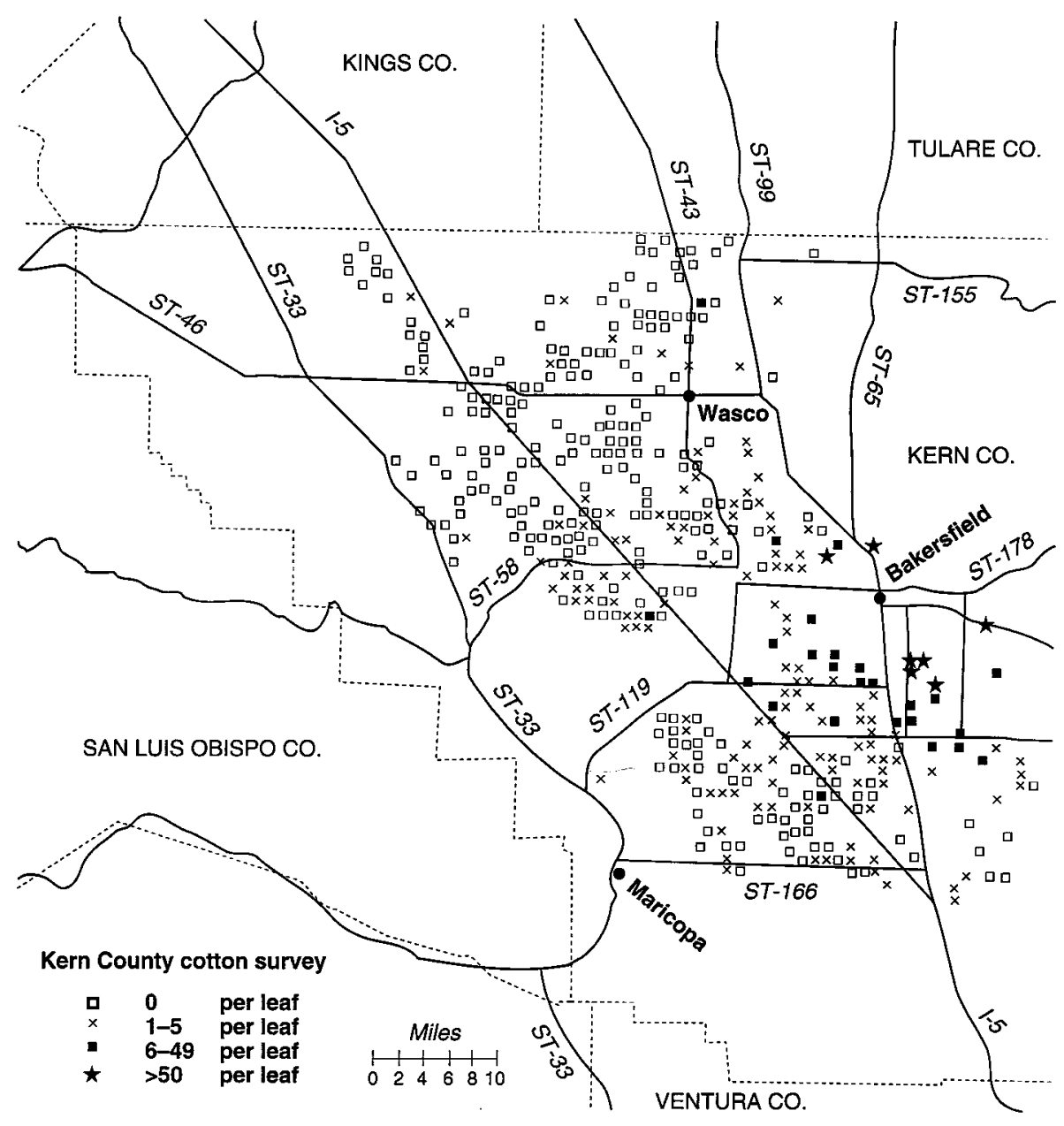

Fig. 2. Kern County cotton fields were sampled in second survey to determine relative densities of whiteflies in the genus Bemisia.

\begin{tabular}{|c|c|c|c|c|c|c|c|c|c|c|c|}
\hline \multicolumn{4}{|c|}{$\begin{array}{l}\text { TABLE 1. Site locations near Bakersfield and plants from which silverleaf } \\
\text { whitefly nymphs and parasites were collected in September } 1992\end{array}$} & \multicolumn{8}{|c|}{$\begin{array}{c}\text { TABLE 2. Percentages of live Bemisia spp. whitefly nymphs, dead nymphs, } \\
\text { and parasitism and live Trialeurodes spp. nymphs ( } T \text {. spp.) sampled from } \\
\text { locations near Bakersfield in September } 1992\end{array}$} \\
\hline Sample & Plant & Location & Map & \multirow[b]{3}{*}{ Sample } & \multirow{2}{*}{\multicolumn{3}{|c|}{ Nymphs }} & \multirow{3}{*}{$\begin{array}{c}\text { Dead } \\
\text { nymphs }\end{array}$} & \multirow{2}{*}{\multicolumn{2}{|c|}{$\begin{array}{l}\text { Parasitized } \\
\text { nymphs }\end{array}$}} & \multirow[b]{3}{*}{$T . \mathrm{spp}$} \\
\hline no. & & & no. & & & & & & & & \\
\hline 1 & Cotton & Airport Dr. X Standard Rd. & 1 & & 3 rd & 4th & Emerged & & 3 rd & 4th & \\
\hline 2 & Cotton & Standard Rd., $1 / 4$ mi. west Jewetta Rd. & 2 & no. & & & & & & & \\
\hline 3 & Cotton & Allen Rd. X Kratzmeyer Rd. & 3 & 1 & 29 & 42 & 26 & 3 & 0 & 0 & 0 \\
\hline 4 & Cotton & Allen Rd., $1 / 4$ mi. south Hageman Rd. & 4 & 2 & 60 & 33 & 6 & 1 & 0 & 0 & 0 \\
\hline 5 & Cotton & Buena Vista Rd. X Stockdale Hwy. & 5 & 3 & 39 & 42 & 19 & 0 & 0 & 0 & 0 \\
\hline 6 & Jimsonweed & Buena Vista Rd. X Stockdale Hwy. & 5 & 4 & 14 & 29 & 47 & 10 & 0 & 0 & 0 \\
\hline 7 & Cotton & Buena Vista Rd. X Pacheco Rd. & 6 & 5 & 15 & 20 & 59 & 6 & 0 & 0 & 0 \\
\hline 8 & Cotton & Old River Rd. X Panama Ln. & 7 & 6 & 33 & 34 & 33 & 0 & 0 & 0 & 0 \\
\hline 9 & Cotton & Gosford Rd. X Panama Ln. & 8 & 7 & 20 & 35 & 42 & 2 & 1 & 0 & 0 \\
\hline 10 & Cotton & Wible Rd. X Panama Ln. & 9 & 8 & 31 & 46 & 21 & 2 & 0 & 0 & 0 \\
\hline 11 & Bindweed & Wible Rd. X Panama Ln. & 9 & 9 & 22 & 29 & 47 & 2 & 0 & 0 & 0 \\
\hline 12 & Pigweed & Wible Rd. X Panama Ln. & 9 & 10 & 8 & 46 & 38 & 7 & 1 & 0 & 0 \\
\hline 13 & Cotton & Union Ave. X Panama Ln. & 10 & 11 & 26 & 41 & 33 & 0 & 0 & 0 & 0 \\
\hline 14 & Lettuce & Union Ave. X Sunset Rd. & & 12 & 72 & 26 & 1 & 1 & 0 & 0 & 0 \\
\hline 15 & & & 11 & 13 & 21 & 45 & 27 & 3 & 3 & 1 & 0 \\
\hline & Broccoll & 1/2 mi. east Fairfax on Buena Vista Rd. & 12 & 14 & 18 & 7 & 4 & 0 & 0 & 0 & 0 \\
\hline 16 & Potato & Fairfax Rd. X Sunset Rd. & 13 & 15 & 97 & 2 & 0 & 0 & 1 & 0 & 0 \\
\hline 17 & Cotton & Fairfax Rd. X Panama Rd. & 14 & 16 & 57 & 43 & 0 & 0 & 0 & 0 & 0 \\
\hline 18 & Potato & Vineland Rd. X Panama Ln. & 15 & 17 & 26 & 25 & 27 & 5 & 0 & 0 & 0 \\
\hline 19 & Cotton & Fairfax Rd. X Hermosa Rd. & 16 & 18 & 27 & 51 & 12 & 1 & 0 & 0 & 0 \\
\hline 20 & Cotton & Edison Rd. X Edison Hwy. & 17 & 19 & 7 & 19 & 66 & 6 & 0 & 0 & 0 \\
\hline 21 & Malva & & 17 & 20 & 26 & 47 & 25 & 2 & 0 & 0 & 0 \\
\hline 22 & Cantaloupe & Edison Rd. X Edison Hwy. & 17 & 21 & 30 & 3 & 4 & 0 & 0 & 0 & 53 \\
\hline 22 & Cantaloupe & Malaga Dr. X Edison Hwy. & 18 & 22 & 75 & 0 & 25 & 0 & 0 & 0 & 0 \\
\hline 23 & Potato & Malaga Dr. X Buena Vista Rd. & 19 & 23 & 36 & 37 & 14 & 1 & 0 & 0 & 0 \\
\hline
\end{tabular}




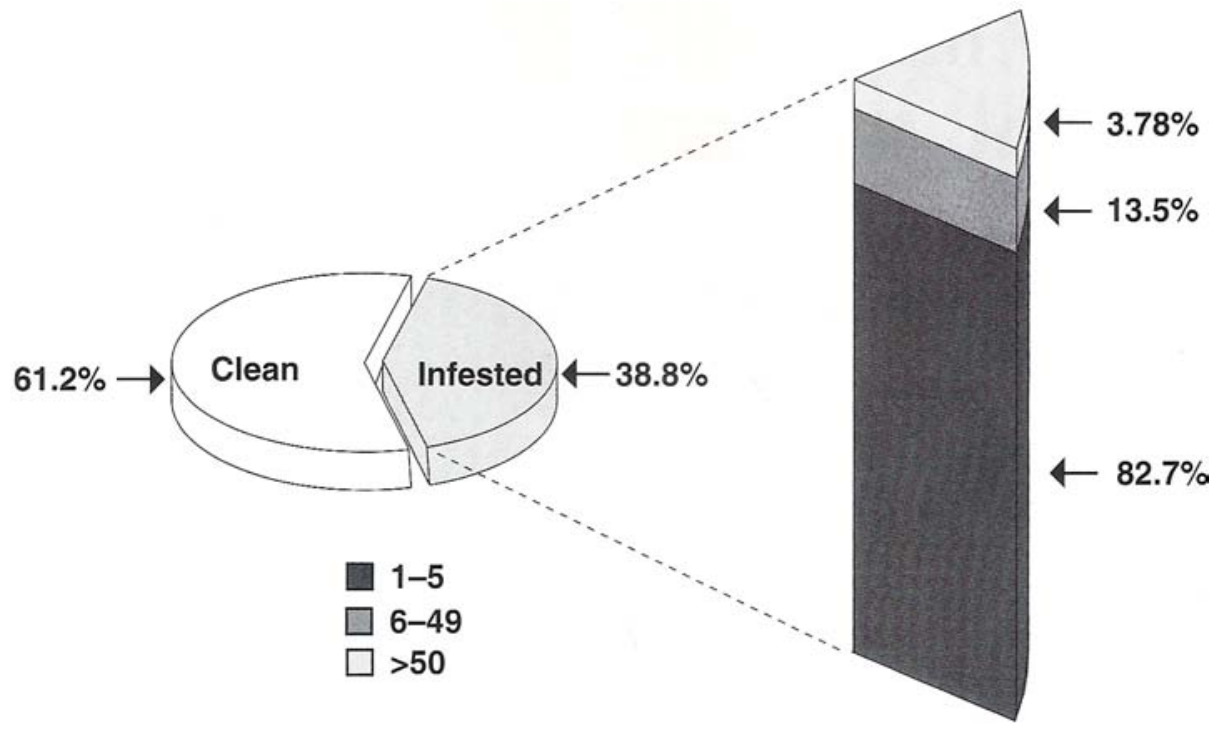

Fig. 3. Percentage of cotton fields sampled had various densities of silverleaf whitefly.

the classical biological control approach that now maintains the ash whitefly, Siphoninus phillyreae (Haliday), at low levels (California Agriculture, January-February 1992). Samples collected from the 19 sites near Bakersfield had only trace levels of parasitism, despite the fact that other beneficial insects, including ladybeetles and lacewings, were observed at one of the most heavily infested fields. Only seven of the 2,300 whitefly nymphs evaluated in our study were parasitized (table 2). In contrast, surveys in the Imperial Valley show average parasitization rates of up to $23 \%$ in cotton and up to $80 \%$ on some weeds.

A second survey in October 1992 documented the extent of the silverleaf whitefly infestation in Kern County cotton fields (fig. 2). Approximately 10\% (or 477 fields) of the county's cotton fields were sampled. Two leaves were taken from each of five plants at each field. Leaves were placed in paper bags, stored at ambient temperatures, and evaluated under dissecting microscopes.

All of the whiteflies collected were morphologically identified in the genus Bemisia, which contains the sweetpotato and silverleaf whiteflies; however, IEF was not conducted. Because $100 \%$ of the whiteflies determined to be Bemisia in the first survey were the silverleaf whitefly, we suspect that whiteflies in this survey also were silverleaf whiteflies. Whitefly nymphs were counted, and fields were categorized according to four levels of infestation: $0=$ no nymphs, low $=1$ to 5 nymphs, moderate $=6$ to 49 nymphs, and high $=>50$ nymphs. In this study, whiteflies were found at $38.8 \%$ of the 477 fields sampled (fig. 3). However, $82.7 \%$ of the infested fields had low levels of infestation.
Fields most heavily infested by whiteflies were located close to Bakersfield (fig. 2).

\section{Conclusions}

Results of our surveys indicate that the range of silverleaf whitefly includes the San Joaquin Valley's southern portion. In December 1991, we identified reproducing populations on backyard ornamental plants in Bakersfield. Because these whiteflies are now in fields around Bakersfield, we believe they have become established and will survive San Joaquin Valley winter conditions. We suspect that population density will decline during winter, as it does in Southern California, and whiteflies may be difficult to locate in the valley in December and January, depending on the availability of host plants. In Southern California, the largest overwintering populations exist on cole crops, with ornamentals - hibiscus, lantana, poinsettia, and verbena - also serving as good hosts.

One factor affecting maximum population densities in a given year is the seasonal accumulation of heat units. In the low desert, warm temperatures early in spring and high day and nighttime temperatures in summer provide heat units that accelerate whitefly population growth and contribute to widespread damaging levels in late summer and early fall. In general, heat units do not accrue as rapidly in the San Joaquin Valley; thus, one would not expect whitefly population levels to reach those recorded in the Imperial Valley. However, there may be isolated warm areas in the San Joaquin where whitefly responses greater than expected could result.

Cultural practices implemented to control silverleaf whitefly in the Imperial Valley include: (1) removing crop residue soon after harvest and limiting weeds in and around fields, to reduce plant material available for whitefly production; (2) decreasing acreage of late-planted spring melons to enable harvest before onset of summer temperatures when whitefly growth rates are highest; (3) terminating cotton growth early in fall to reduce whitefly host material at a time when the population is growing exponentially; and (4) avoiding planting fall melons to eliminate a host on which whitefly reproduction is high.

The seasonal population dynamics and ecology of the silverleaf whitefly in the southern San Joaquin Valley have not been described, so it is not known whether similar cultural techniques implemented there would succeed. We are unable to relate such factors as varietal differences, planting near urban areas, nor planting near particular crops to subsequent levels of whiteflies. We predict, however, that the most severe infestations will occur in late-season plantings or in crop cultivars with a protracted growth and maturation period.

When possible, early planting and harvesting of susceptible crops and their management for early maturity should be practiced. For example, the longer maturation time required for 'Pima' cotton cultivars may make them more susceptible to the late-season whitefly population increases than the 'Acala' cultivars.

The lack of proven control measures notwithstanding, solutions to the problems caused by the silverleaf whitefly likely will have to be implemented areawide to be effective. For that reason, we suggest that local working groups, similar to the Imperial Valley Whitefly Management Committee, be formed, in conjunction with Agricultural Commissioners, California Department of Food and Agriculture scientists, and UC Cooperative Extension and research personnel, to monitor development of damaging silverleaf whitefly levels and to implement control strategies as they become available.

N. M. Gruenhagen and T. M. Perring are

Graduate Research Assistant and Associate Professor, respectively, in the Department of Entomology, UC Riverside. L. G. Bezark is Senior Environmental Research Scientist, Biological Control Program, California Department of Food and Agriculture. D. M. Daoud is Staff Biologist, Kern County Agricultural Commissioners Office, and T. F. Leigh is Professor Emeritus, Department of Entomology, UC Davis, stationed at Shafter Cotton Research Station.

The authors thank Charles A. Farrar, Arthur C. Cooper, Dan Keaveny, and Charlie Hodson for their many contributions to this project. 